\title{
PENGARUH SUHU RUANG PELEBURAN DAN TEKANAN GAS ALIR TERHADAP OUTPUT SERBUK TIMAH YANG DIHASILKAN DARI SISTEM ATOMISASI GAS ARGON PANAS
}

\author{
Abdul Basyir ${ }^{\mathrm{a}}$, Didik Aryanto ${ }^{\mathrm{b}}$, Agus Sukarto Wismogroho $^{\mathrm{c}}$, \\ Wahyu Bambang Widayatno ${ }^{\mathrm{d}}$
}

Pusat Penelitian Fisika, Lembaga Ilmu Pengetahuan Indonesia

Email: a)abdul7basyir@gmail.com, ${ }^{\text {b) }}$ didikpt @ gmail.com, ${ }^{\mathrm{c})}$ agussukarto@gmail.com, ${ }^{\mathrm{d})}$ wahyubw@ gmail.com

\begin{abstract}
Abstrak
Serbuk timah merupakan komponen utama dalam pembuatan pasta solder. Salah satu requirement dari serbuk yang diperlukan adalah ukuran partikel serbuk maksimal 45 mikron. Dimana semakin kecil ukuran dari partikel serbuk timah dalam komposisi pasta solder tersebut, maka harga dari pasta solder akan semakin meningkat. Salah satu metode yang dapat dilakukan untuk menghasilkan serbuk timah adalah atomisasi gas. Tujuan dari penelitian ini untuk menambah pengetahuan tentang pengaruh dari tekanan dan suhu dari ruang peleburan terhadap ukuran dari output serbuk timah yang dihasilkan. Eksperimen dari penelitian ini menggunakan desain sistem atomisasi gas panas, dengan media gas berupa argon. Hasil penelitian dengan menggunakan desain sistem atomisasi gas ini, menunjukkan bahwa suhu ruang peleburan timah dan tekanan gas alir saat atomisasi mempengaruhi distribusi ukuran dari partikel serbuk timah yang dihasilkan, semakin tinggi suhu ruang peleburan dan tekanan gas alir yang digunakan, maka ukuran partikel serbuk timah yang dihasilkan akan semakin kecil.
\end{abstract}

Kata-kata kunci: Serbuk; Atomisasi Gas Argon Panas; Tekanan Gas Alir; Suhu Ruang Peleburan.

\begin{abstract}
The tin powder is a major component in making solder paste. One of the requirements of the required powder was a maximum particle size of 45 microns. The composition of solder paste with a smaller particle size has a higher price. One method that can be used to produced tin powder was gas atomization. Furthermore, the purpose of this research was to increase knowledge regarding the effect of chamber melting temperature and gas flow pressure on the particle size of tin powder output. The experiment of this research was using the design of the hot gas atomization system, with the gas type is argon. The results of the research showed that the chamber melting temperature and gas flow pressure have an effect on the particle size of the tin powder. Where the higher chamber melting temperature was producing the smaller particle size of tin powder. So do with the gas flow rate pressure parameter, the higher gas flow rate pressure was generating the smaller particle size of tin powder, but for this case, when using gas flow pressure about 20 bar, it was happening the backpressure phenomenon. It was caused by the nozzle design of this gas atomization system.
\end{abstract}

Keywords: Powder; Hot Argon Gas Atomization; Gas Flow Pressure; Chamber Melting Temperature. 


\section{PENDAHULUAN}

Permintaan dunia industri dan lembaga penelitian terhadap serbuk timah semakin meningkat. Serbuk tersebut dapat digunakan dalam aplikasi sintering, soldering, painting, addictive manufacturing, $3 D$ printing, chemical formulations, pyrotechnics, dan lain sebagainya [1-2]. Dimana serbuk timah yang diminta adalah serbuk yang berukuran kecil, dengan kemurnian yang tinggi, dan berbentuk bulat [3]. Secara spesifik, untuk aplikasi soldering, ukuran partikel serbuk yang banyak digunakan saat ini adalah tipe 3 dan 4, yang berukuran $25-45 \mu \mathrm{m}$ dan $20-38 \mu \mathrm{m}$ [4]. Hal ini dikarenakan, dengan ukuran serbuk yang kecil dan bentuk yang bulat, maka densitas dari serbuk akan meningkat dengan laju alir yang baik. Adapun serbuk tersebut dapat dihasilkan melalui beberapa proses seperti proses atomisasi, proses mekanik, proses kimia, proses elektroda berputar, dan lain sebagainya [5-6].

Proses atomisasi merupakan metode yang sering digunakan untuk menghasilkan serbuk, baik itu menggunakan media gas, air, plasma, sentrifugal, maupun kombinasi. Beberapa metode kombinasi yang pernah dilakukan diantaranya seperti (1) metode centrifugal hydraulic atomization dan gas atomization yang menghasilkan ukuran partikel serbuk dari $7-200 \mu \mathrm{m}$ [7], (2) metode pressureswirls atomiser dan ring-gas nozzle yang menghasilkan partikel serbuk timah $25-125 \mu \mathrm{m}$ [8], dan (3) metode gas atomization dan centrifugal break-up yang menghasilkan ukuran serbuk timah 10 $15 \mu \mathrm{m}$ [9]. Ukuran partikel serbuk yang dihasilkan melalui metode atomisasi kombinasi sudah kecil, namun penggunaan metode atomisasi kombinasi relatif memerlukan peralatan yang lebih banyak, sehingga menghasilkan biaya yang lebih tinggi, begitu juga dengan metode atomisasi plasma yang mampu menghasilkan bentuk dari serbuk yang bulat, namun menghasilkan produktivitas rendah dan biaya yang lebih tinggi dibanding metode yang lain [10]. Adapun metode atomisasi air kurang mampu menghasilkan serbuk dengan kemurnian yang baik [11], sedangkan metode atomisasi sentrifugal memerlukan kecepatan rotasi yang tinggi untuk menghasilkan serbuk yang baik [12].

Oleh karena itu, dalam penelitian ini akan dilakukan pembuatan serbuk melalui proses atomisasi gas dengan menggunakan inert gas berupa argon. Dimana metode atomisasi gas adalah leading technology untuk menghasilkan serbuk logam dengan efisiensi produksi yang tinggi dan biaya yang lebih ekonomis [13-14]. Penggunaan inert gas adalah untuk memastikan proses atomisasi tersebut menghasilkan serbuk dengan impuritas yang baik dan bentuk yang bulat [15-16]. Selain itu, untuk menghasilkan ukuran partikel serbuk yang kecil, akan menggunakan gas alir dengan suhu yang panas. Menurut Hopkins, semakin tinggi suhu dari gas alir yang digunakan, maka partikel serbuk yang dihasilkan akan semakin kecil [17]. Adapun untuk melihat distribusi dari ukuran partikel serbuk yang dihasilkan, maka akan dilakukan variasi dari besar tekanan gas alir dan suhu ruang peleburan. Dalam penelitian ini akan difokuskan untuk melihat pengaruh tekanan gas alir dan suhu ruang peleburan terhadap ukuran partikel serbuk yang dihasilkan. Harapannya, semakin tinggi tekanan dan suhu ruang peleburan yang digunakan, maka ukuran partikel serbuk yang dihasilkan akan semakin kecil.

\section{MATERIAL DAN METODE}

Penelitian ini dilakukan dengan metode eksperimen menggunakan atomisasi gas, dengan desain atomisasi gas yang dapat dilihat pada gambar 1. Proses eksperimen ini dimulai dengan mengatur besar suhu dari ruang peleburan dan suhu gas alir melalui mesin pengontrol suhu. Dimana dalam penelitian ini dibuat dua skema eksperimen yaitu skema (1) suhu dan tekanan gas alir dibuat konstan yaitu sebesar $150{ }^{\circ} \mathrm{C}$ dan 8 bar, sedangkan suhu ruang peleburan dibuat tiga variasi yaitu 600,700 , dan $800{ }^{\circ} \mathrm{C}$, dan skema (2) suhu gas alir tetap dibuat konstan yaitu $150{ }^{\circ} \mathrm{C}$, dengan suhu ruang peleburan juga dibuat konstan yaitu $600{ }^{\circ} \mathrm{C}$, namun tekanan gas alir dibuat variasi yaitu 4, 6, 8, dan 20 bar. Setelah suhu pada gas alir dan ruang peleburan telah mencapai besar yang diinginkan, maka kemudian dimasukkan sebanyak 50 gram granular timah padat kedalam ruang peleburan, dan dimana lubang dari ruang peleburan menuju ruang utama atomisasi masih dalam kondisi tertutup. Setelah granular timah padat tersebut melebur, maka gas alir kemudian dialirkan menuju ruang utama atomisasi dengan besar tekanan sesuai dengan skema dalam penelitian ini. Setelah itu, penutup lubang dari ruang peleburan dibuka, sehingga timah leburan tersebut akan menuju ruang utama 
atomisasi dan teratomisasi oleh aliran gas argon yang sebelumnya telah dialirkan kedalam ruang utama atomisasi tersebut.

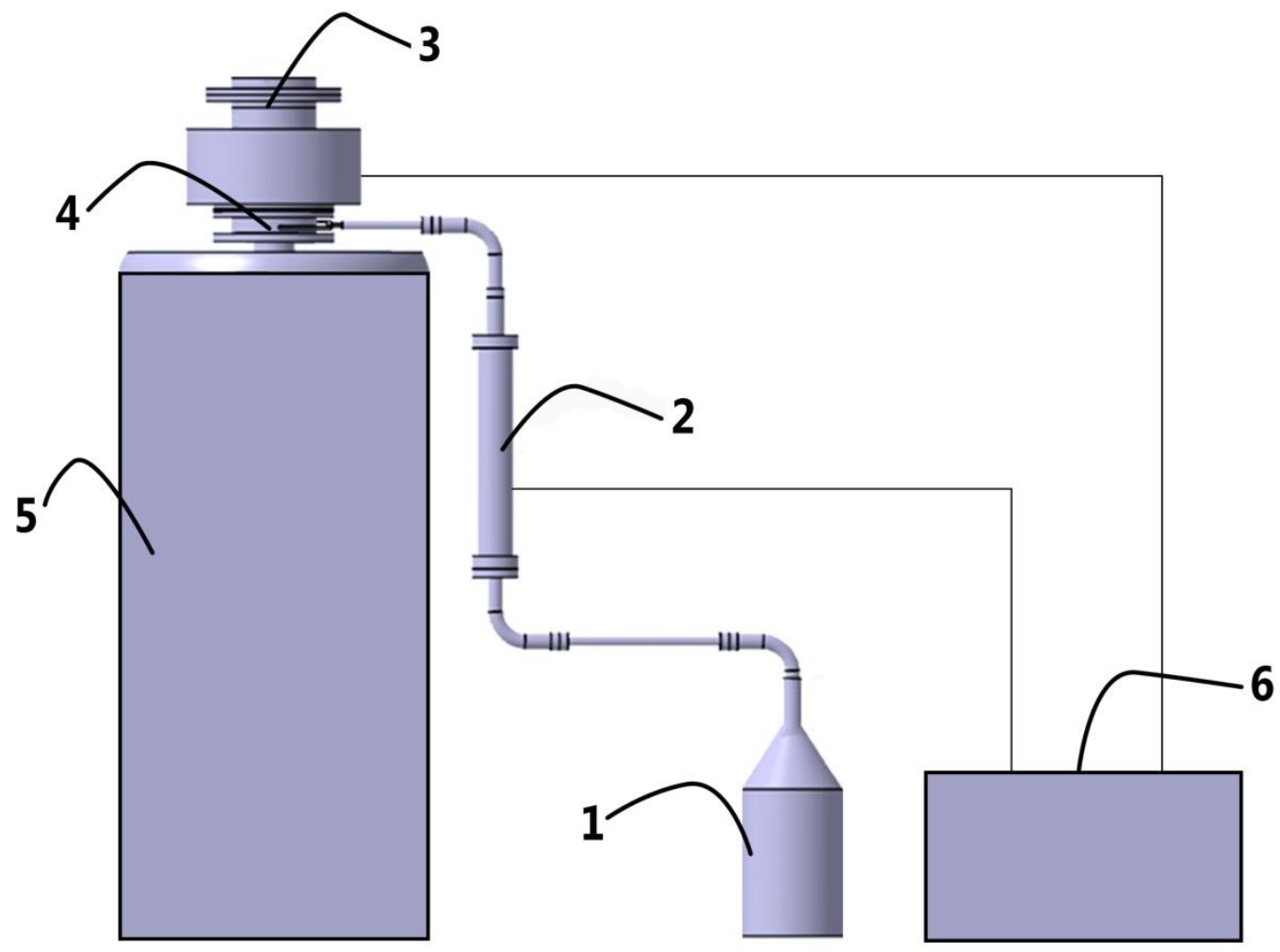

GAMBAR 1. Desain dari Sistem Atomisasi Gas Panas: (1) Sistem Tabung Gas Argon, (2) Ruang Pemanas Gas, (3) Ruang Peleburan Logam, (4) Ruang Utama Atomisasi, (5) Ruang Penampungan Serbuk Sistem Tidak Vakum, dan (6) Mesin Pengontrol Suhu

Output serbuk yang dihasilkan akan didistribusikan ukuran-nya menggunakan tiga jenis saringan yaitu (1) saringan 500 mesh yang dapat menyaring partikel serbuk berukuran $\leq 25 \mu \mathrm{m}$, (2) saringan 400 mesh yang dapat menyaring partikel serbuk berukuran antara $\leq 37 \mu \mathrm{m}$, dan (3) saringan 100 mesh yang dapat menyaring partikel serbuk berukuran antara $\leq 150 \mu \mathrm{m}$. Setiap serbuk yang didapat dari masing-masing saringan tersebut akan diukur massanya menggunakan timbangan digital, kemudian dibuat grafik distribusi partikel serbuk yang dihasilkan dari masing-masing parameter eksperimen. Selain itu, dalam penelitian ini juga akan dilihat efisiensi serbuk (persentase output terhadap input) yang dihasilkan dari desain atomisasi gas ini.

\section{HASIL DAN DISKUSI}

Eksperimen dengan menggunakan skema 1 yaitu suhu dan tekanan gas alir dibuat konstan sebesar $150{ }^{\circ} \mathrm{C}$ dan 8 bar, sedangkan suhu dari ruang peleburan dibuat tiga variasi yaitu 600,700 , dan 800 ${ }^{\circ} \mathrm{C}$. Dimana skema ini dilakukan untuk mengamati pengaruh suhu dari ruang peleburan terhadap output serbuk timah yang dihasilkan. Adapun dari skema ini diketahui bahwa untuk output serbuk berukuran $1-25 \mu \mathrm{m}$, suhu ruang peleburan $800{ }^{\circ} \mathrm{C}$ menghasilkan output, 3.4 kali lebih banyak dibandingkan dengan menggunakan suhu ruang peleburan $600{ }^{\circ} \mathrm{C}$ (lihat gambar 2). Selain itu, dengan menggunakan suhu ruang peleburan $800{ }^{\circ} \mathrm{C}$, dihasilkan output serbuk yang berukuran $>100$ $\mu \mathrm{m}$ lebih sedikit, dibandingkan dengan menggunakan suhu ruang peleburan $600{ }^{\circ} \mathrm{C}$ dan $700{ }^{\circ} \mathrm{C}$. Dimana output dengan kategori $>100 \mu \mathrm{m}$ ini didominasi oleh droplet dari ingot timah yang tidak teratomisasi dan/atau tidak teratormisasi dengan baik, sehingga kebanyakan masih berbentuk lempengan padat kecil dengan bentuk tidak beraturan.

Pada saat suhu ruang peleburan ditingkatkan, maka viskositas dari leburan timah akan semakin menurun, penurunan nilai viskositas ini sangat penting untuk memastikan bahwa proses mengalirnya 
leburan timah dari ruang peleburan menuju ruang atomisasi berjalan dengan lancar, sehingga leburan timah akan teratomisasi dengan baik. Selain itu, dengan suhu ruang peleburan semakin tinggi, maka suhu pada ruang atomisasi akan terjaga tidak terlalu jauh dengan suhu di ruang peleburan. Hal ini berguna untuk memastikan bahwa leburan timah yang telah teratomisasi akan mulai mengalami solidifikasi, setelah berada dalam bentuk yang seimbang, yaitu bentuk rasio terkecil antara luas permukaan dengan volume cairan-nya, bulat. Leburan timah dengan viskositas yang lebih rendah menyebabkan droplet dari leburan tersebut akan lebih mudah terpecah menjadi serbuk yang kecil [18], pada saat ditumbuk oleh aliran gas atomisasi (dalam hal ini adalah gas argon). Oleh karena itu, suhu ruang peleburan $800{ }^{\circ} \mathrm{C}$, menghasilkan ukuran partikel antara $1-25 \mu \mathrm{m}$ lebih banyak dibandingkan dengan suhu ruang peleburan $600{ }^{\circ} \mathrm{C}$ dan $700{ }^{\circ} \mathrm{C}$.

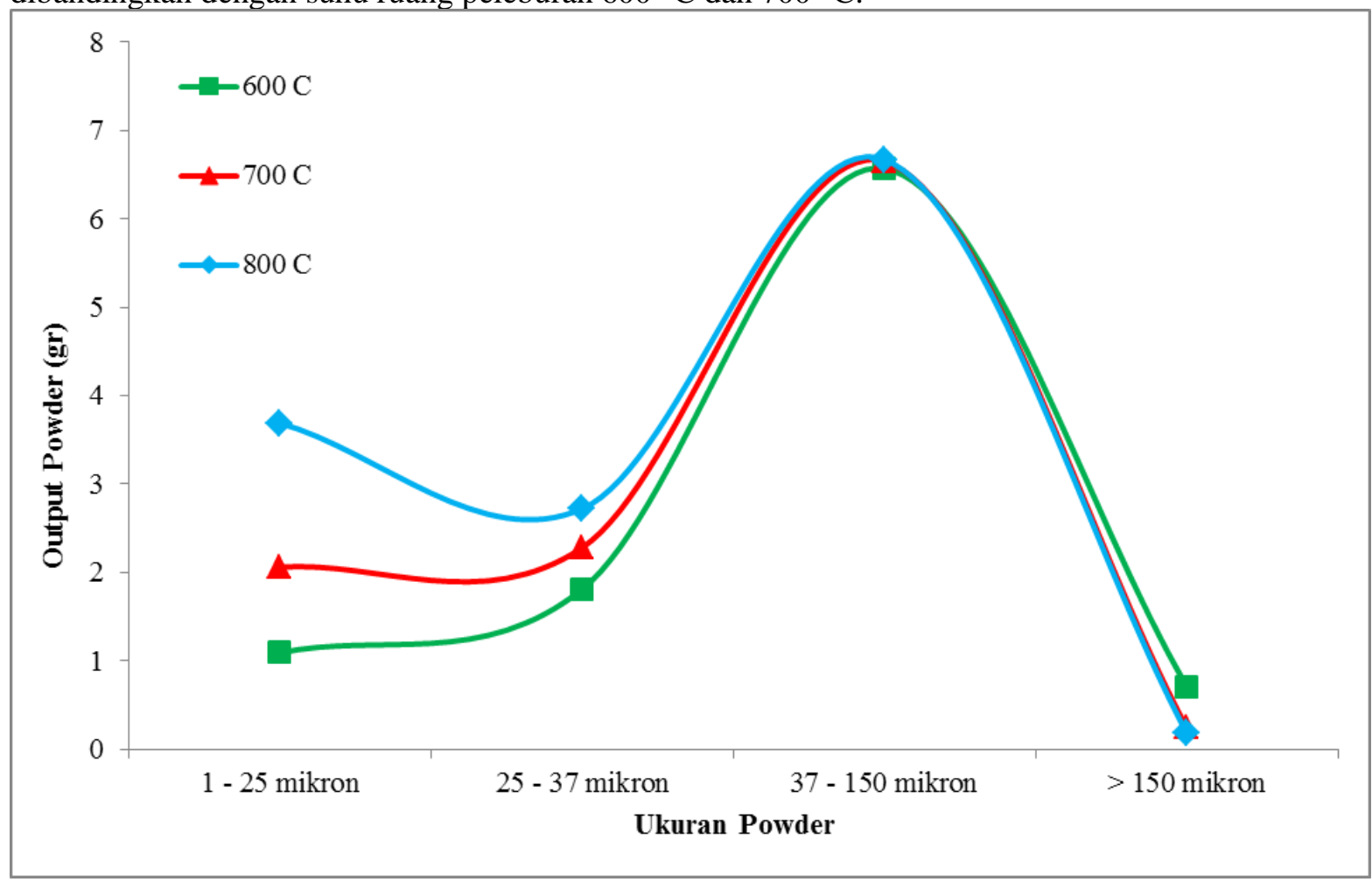

GAMBAR 2. Grafik Pengaruh Suhu dari Ruang Peleburan terhadap Kuantitas dari Output Serbuk Timah yang dihasilkan pada Distribusi Ukuran $1-25 \mu \mathrm{m}, 25-37 \mu \mathrm{m}, 37-150 \mu \mathrm{m}$, dan $>150 \mu \mathrm{m}$

Eksperimen dengan menggunakan skema 2 yaitu suhu gas alir dan suhu ruang peleburan dibuat konstan sebesar $150{ }^{\circ} \mathrm{C}$ dan $600{ }^{\circ} \mathrm{C}$, sedangkan tekanan dari gas alir dibuat empat variasi yaitu 4,6 , 8, dan 20 bar. Dimana skema ini dilakukan untuk mengamati pengaruh tekanan dari gas alir terhadap output serbuk timah yang dihasilkan. Adapun dari skema ini diketahui bahwa semakin tinggi tekanan yang digunakan, maka semakin banyak serbuk timah berukuran $1-37 \mu \mathrm{m}$ yang dihasilkan (lihat gambar 3). Akan tetapi dalam eksperimen ini, pada saat digunakan tekanan sebesar 20 bar, maka terjadi back pressure, yang merupakan proses terdorongnya leburan timah dari ruang peleburan menuju kebagian atas ruang peleburan, menjauhi ruang atomisasi. Hal ini disebabkan oleh desain dari nosel pada sistem atomisasi ini yang berada didalam ruang atomisasi, sehingga tidak mendukung penggunaan tekanan gas alir yang tinggi. Adapun back pressure ini menyebabkan terhambatnya proses pembuatan serbuk, akibat adanya sumbatan dari gas alir pada lubang lelehan leburan timah, sehingga lebih banyak leburan timah yang tidak mengalami atomisasi. Hal ini dapat dilihat dari kuantitas serbuk berukuran $>150 \mu \mathrm{m}$ dan total serbuk yang dihasilkan menggunakan tekanan gas alir sebesar 20 bar, yang jauh lebih sedikit dihasilkan, dibandingkan dengan menggunakan tekanan gas alir sebesar 4, 6, dan 8 bar (lihat tabel 1).

Adapun penggunaan tekanan gas alir sebesar 8 bar mampu menghasilkan serbuk berukuran $1-37$ $\mu \mathrm{m}$ lebih banyak daripada penggunaan tekanan gas alir, 4 dan 6 bar, karena tekanan dapat 
mempengaruhi kecepatan gas [16], dimana semakin tinggi kecepatan gas atomisasi, maka ukuran partikel serbuk yang dihasilkan akan semakin kecil [19]. Hal tersebut dapat dilihat pada saat tekanan gas alir yang digunakan sebesar 4 bar, maka kuantitas serbuk berukuran $1-37 \mu \mathrm{m}$ berkurang, namun kuantitas serbuk berukuran lebih besar yaitu $37-150 \mu \mathrm{m}$ menjadi bertambah, lebih banyak dibandingkan dengan menggunakan tekanan gas alir sebesar 6 dan 8 bar. Semakin cepat gas alir dan semakin besar tekanan dari gas alir, maka energi untuk memecah droplet dari leburan timah akan semakin besar dan semakin cepat, sehingga droplet leburan timah yang mengalir dari ruang peleburan akan ditumbuk secara optimal mencapai bentuk terkecil oleh energi kinetik yang dihasilkan dari kecepatan gas alir tersebut, dan kuantitas dari droplet leburan timah tersebut akan teratomisasi secara keseluruhan.

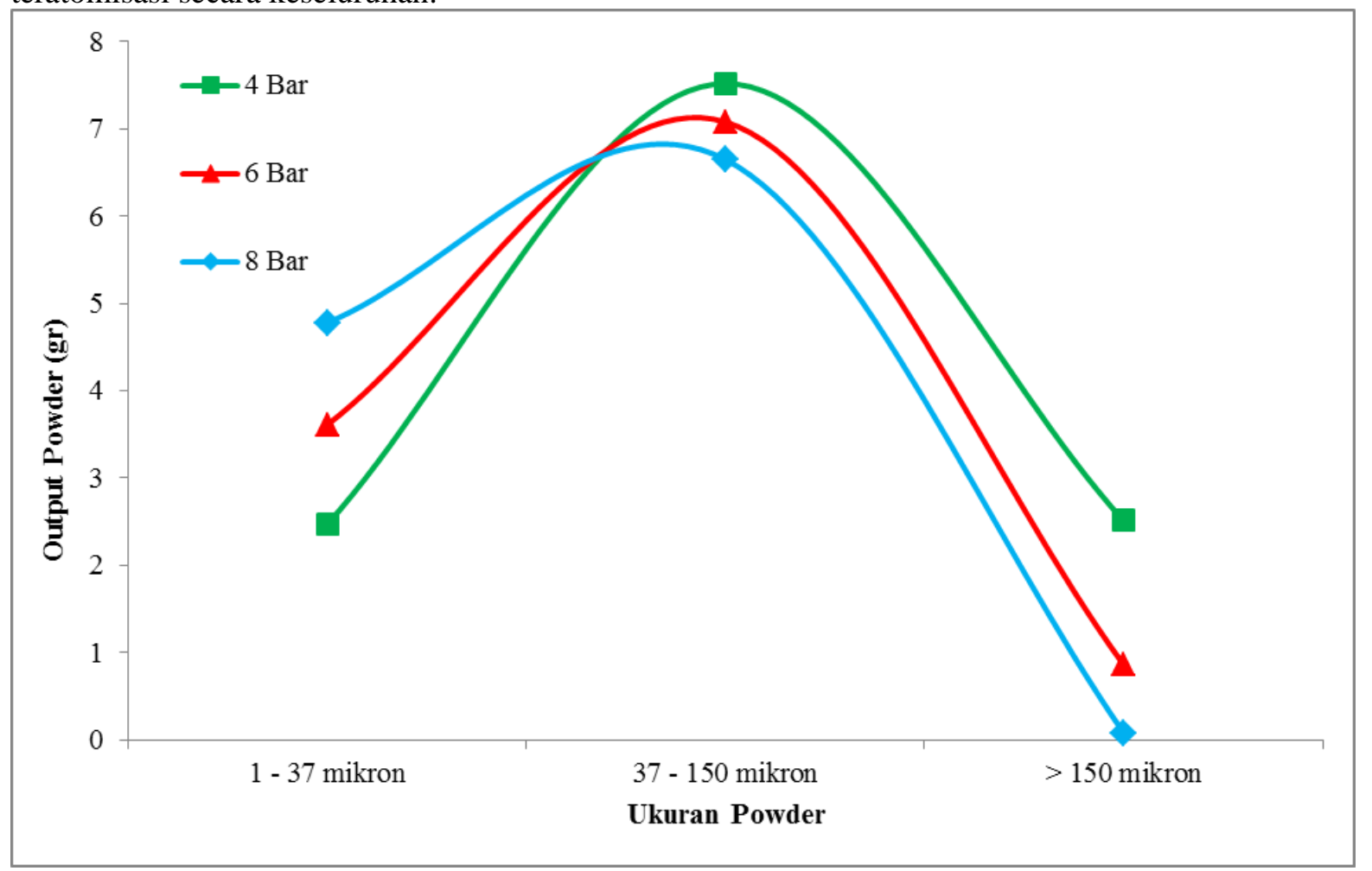

GAMBAR 3. Grafik Pengaruh Tekanan Gas Alir terhadap Kuantitas dari Output Serbuk Timah yang dihasilkan pada Distribusi Ukuran $1-37 \mu \mathrm{m}, 37-150 \mu \mathrm{m}$, dan $>150 \mu \mathrm{m}$

TABEL 1. Distribusi Ukuran Serbuk dan Efisiensi Output Serbuk yang Dihasilkan dari Sistem Atomisasi Gas Panas dengan Melihat Pengaruh Perubahan Tekanan Gas Alir

\begin{tabular}{ccccccc}
\hline \multirow{2}{*}{$\begin{array}{c}\text { Kode } \\
\text { Sampel }\end{array}$} & $\begin{array}{c}\text { Tekanan Gas Alir } \\
\text { (Bar) }\end{array}$ & \multicolumn{5}{c}{ Output Serbuk (gr) } \\
\cline { 3 - 6 } & 4 & $1-37$ mikron & $37-150$ mikron & $>150$ mikron & Total & \\
\hline 1 & 6 & 3.47 & 7.52 & 2.51 & 9.99 & $20 \%$ \\
2 & 8 & 4.61 & 7.08 & 0.86 & 10.69 & $21 \%$ \\
3 & 20 & 1.73 & 6.65 & 0.08 & 11.43 & $23 \%$ \\
4 & 10.86 & 5.90 & 5.31 & 7.63 & $15 \%$ \\
& Total (gr) & 3.62 & 7.08 & 3.45 & 32.11 & $21 \%$ \\
& Rata-Rata (gr) & & 1.15 & 10.70 & $21 \%$ \\
\hline
\end{tabular}




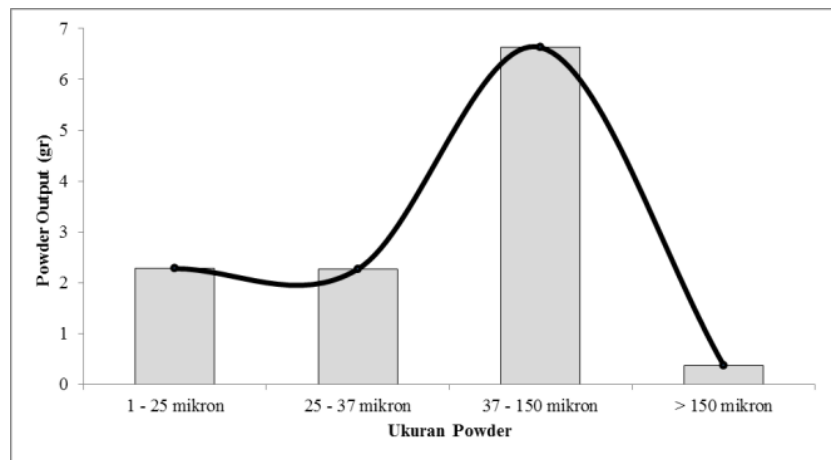

(a)

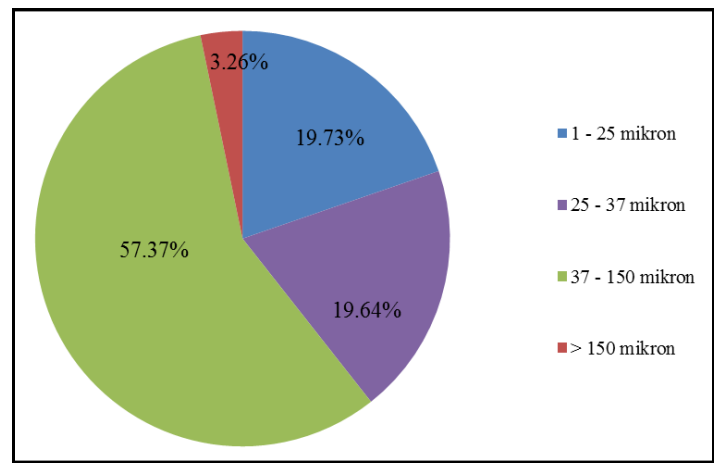

(b)

GAMBAR 4. Grafik (a) Histogram dan (b) Persentase dari Distribusi Rata-Rata Ukuran dari Partikel Serbuk Timah yang Dihasilkan dengan Suhu Ruang Peleburan sebesar 600, 700, dan $800{ }^{\circ} \mathrm{C}$

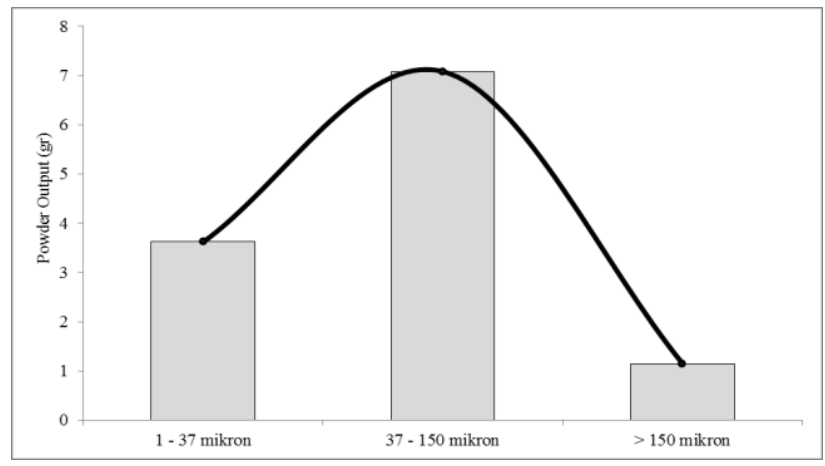

(a)

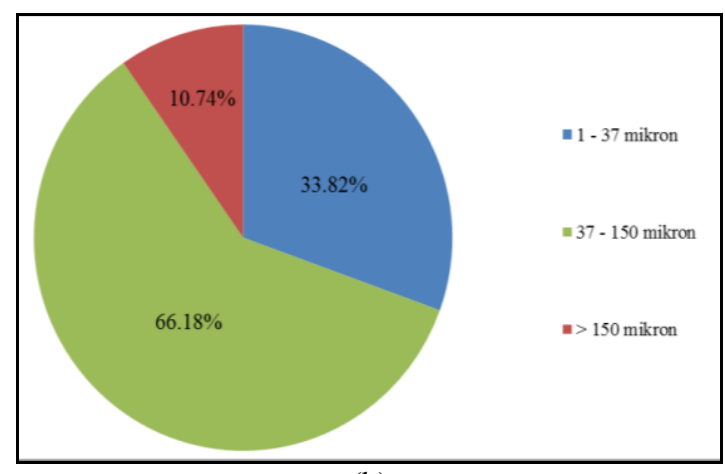

(b)

GAMBAR 5. Grafik (a) Histogram dan (b) Persentase dari Distribusi Rata-Rata Ukuran dari Partikel Serbuk Timah yang Dihasilkan dengan Tekanan Gas Alir 4, 6, dan 8 Bar.

Pada eksperimen dengan skema 1 dan 2 ini, ukuran partikel yang dihasilkan didominasi oleh ukuran antara $37-150 \mu \mathrm{m}$, dengan persentase > 55\% (lihat gambar 4 dan 5). Oleh karena itu, merujuk kepada ukuran partikel untuk pasta solder, yaitu tipe 3 berukuran $25-45 \mu \mathrm{m}$, dan tipe 4 berukuran $20-38 \mu \mathrm{m}$ [4], maka sistem powderisasi dengan desain ini belum optimal dalam menghasilkan serbuk timah dengan ukuran yang sesuai untuk bahan baku pasta solder. Apalagi dalam eksperimen ini menggunakan suhu ruang peleburan yang relatif tinggi, sehingga biaya operasional untuk menghasilkan serbuk tersebut akan semakin meningkat. Akan tetapi, serbuk timah yang mempunyai ukuran $>45 \mu \mathrm{m}$ dapat digunakan untuk aplikasi lain, seperti timah kimia menjadi timah oksida, atau digunakan sebagai campuran pada bidang piroteknik untuk membuat smoke powder, dan lain sebagainya. Adapun efisiensi dari sistem ini masih rendah, dari input yang dimasukkan sebesar 50 gram, dihasilkan output sekitar $10-11$ gram, atau sekitar $21-23 \%$. Hal ini disebabkan karena ruang penampungan serbuk, belum menggunakan sistem vakum, sehingga ukuran partikel serbuk yang sangat kecil, relatif sulit dikondisikan.

\section{KESIMPULAN}

Sistem atomisasi gas argon panas dengan menggunakan system tabung gas dan system penampungan serbuk tidak vakum ini, menghasilkan serbuk timah berukuran $1-150 \mu \mathrm{m}$. Dimana ukuran serbuk timah yang dihasilkan, didominasi oleh ukuran $37-150 \mu \mathrm{m}$. Suhu ruang peleburan sebesar $800{ }^{\circ} \mathrm{C}$ menghasilkan kuantitas serbuk timah berukuran $1-25 \mu \mathrm{m}$ lebih banyak daripada suhu ruang peleburan 600 dan $700{ }^{\circ} \mathrm{C}$. Begitu juga dengan tekanan gas alir sebesar 8 bar mampu menghasilkan kuantitas serbuk berukuran $1-25 \mu \mathrm{m}$ lebih banyak dibandingkan dengan menggunakan tekanan gas alir sebesar 4 dan 6 bar. Adapun efisiensi output terhadap input dari sistem 
ini hanya mencapai $21-23 \%$, atau dari 50 gram input berupa timah granular, hanya dihasilkan sebesar 11 gram serbuk timah.

\section{UCAPAN TERIMAKASIH}

Peneliti mengucapkan terimakasih kepada Pusat Penelitian Fisika - Lembaga Ilmu Pengetahuan Indonesia, PT. Timah Industri, dan KEMENRISTEK/BRIN yang telah memberikan dukungan berupa fasilitas eksperimen, fasilitas pengujian, bahan penelitian, dan dana penelitian, sehingga penelitian ini dapat terlaksana dengan baik. Selain itu, peneliti juga mengucapkan secara khusus kepada Dr. Agus Sukarto Wismogroho yang telah membimbing dan mengarahkan peneliti dalam penulisan paper ini.

\section{REFERENSI}

1. S. Cheng, C. M. Huang and M. Pecht, "A review of lead-free solders for electronics applications," Microelectronics Reliability, vol. 75, pp. 77-95, 2017.

2. K. Kassym and A. Perveen, "Atomization processes of metal powders for 3D printing," Materialstoday: Proceedings, pp. 1-7, 2020.

3. R. Li et al., "Fabrication of fine-grained spherical tungsten powder by radio frequency (RF) inductively coupled plasma spheroidization combined with jet milling," Advanced Powder Technology, vol. 28, pp. 3158-3163, 2017.

4. T. C. Lin et al., "Optimization of gas atomization processes in production of ultra-fine solder powder," Proceeding ICLASS, pp. 1-8, 2006.

5. L. V. M. Antony and R. G. Reddy, "Processes for production of high-purity metal powders," JOM, vol. 55, no. 3, pp. 14-18, 2003.

6. J. Tang et al., "Characteristics and atomization behavior of Ti-6Al-4V powder produced by plasma rotating electrode process," Advanced Powder Technology, vol. 30, pp. 2330-2337, 2019.

7. S. Lagutkin et al., "Atomization process for metal powder," Materials Science and Engineering, vol. A 383, pp. 1-6, 2004.

8. L. Achelis and V. Uhlenwinkel, "Characteritation of metal powders generated by a pressure-gasatomiser," Materials Science \& Engineering, vol. A 477, pp. 15-20, 2008.

9. K. Minagawa et al., "Production of fine spherical lead-free solder powders by hybrid atomization," Scence and Technology of Advanced Materials, vol. 6, pp. 325-329, 2005.

10. M. Entezarian et al., "Plasma atomization: a new process for the production of fine," spherical powders, JOM 48, pp. 53-55, 1996.

11. L. Zhang et al., "A comparative inverstigation on MIM418 superalloy fabricated using gas- and water- atomized powders," Powder Technology, vol. 286, pp. 798-806, 2015.

12. P. Sungkhaphaitoon, T. Plookphol and S. Wisutmethangoon, "Design and development of a centrifugal atomizer for producing zinc metal powder," International Journal of Applied Physics and Mathematics, vol. 2, pp. 77-82, 2012.

13. I. E. Anderson and R. L. Terpstra, "Progress toward gas atomization processing with increased uniformity and control," Materials Science and Engineering, A326, pp. 101-109, 2002.

14. S. Chen and B. Huang, "Status and development of gas atomization for production of metal powders," Powder Metallurgy Technology, vol. 22, pp. 297-302, 2004.

15. S. Ozbilen, A. Unal and T. K. Sheppard, "Influence of atomizing gases on the oxide-film morphology and thickness of aluminum powders," Oxidation of Metals, vol. 53, pp. 1-23, 2000.

16. S. Ozbilen, "Influence of atomising gas pressure on particle shape of $\mathrm{Al}$ and $\mathrm{Mg}$ powders," Powder Technology, vol. 102, pp. 109-119, 1999.

17. W. G. Hopkins, "Hot gas atomisation," Metal Powder Report, vol. 58, p. 53, 2003.

18. A. Unal, "Effect of processing variables on particle size in gas atomization of rapidly solidified aluminium powders," Materials Science and Technology, vol. 3, pp. 1029-1039, 1987.

19. S. Hussain et al., "Effect of hot gas atomization on spary forming of steel tubes using a closecoupled atomizer (CCA)," Journal of Materials Processing Technology, vol. 282, pp. 1-8, 2020. 
